\title{
Polymeric Structures in Aluminium and Gallium Halides
}

\author{
Z. Akdeniz, M. Çaliskan ${ }^{a}$, Z. Çiçek, and M. P. Tosi ${ }^{\mathrm{b}}$ \\ Physics Department, University of Istanbul, Istanbul, Turkey \\ a Department of Physics, Trakya University, Edirne, Turkey \\ ${ }^{\mathrm{b}}$ INFM and Classe di Scienze, Scuola Normale Superiore, Pisa, Italy \\ Reprint requests to Prof. M. P. T.; Fax: +39-50-563513; E-mail: tosim@sns.it \\ Z. Naturforsch. 55 a, 575-580 (2000); received February 18, 2000
}

\begin{abstract}
The anionic species $\left(\mathrm{Al}_{n} \mathrm{X}_{3 n+1}\right)^{-}$with $\mathrm{X}=\mathrm{Cl}$ or $\mathrm{Br}$ and $n \geq 1$ have been recognized for a number of years to form in acidic liquid mixtures of aluminium chloride or bromide with the corresponding halides of alkali or organic cations, in relative proportions which vary with the composition of the mixture. In this work we evaluate the structure and the energetics of such polymeric series in a comparative study of $\mathrm{Al}$ and $\mathrm{Ga}$ compounds. To this end we first extend an earlier study of the ionic interactions in the $\mathrm{Al}_{2} \mathrm{Cl}_{6}$ molecule [Z. Akdeniz and M. P. Tosi, Z. Naturforsch. 54a, 180 (1999)] to determine microscopic ionic models for $\mathrm{Ga}_{2} \mathrm{Cl}_{6}, \mathrm{Al}_{2} \mathrm{Br}_{6}$, and $\mathrm{Ga}_{2} \mathrm{Br}_{6}$. The models are then used (i) to evaluate the polymeric clusters for $n \leq 4$ in the two trivalent-metal chlorides, and (ii) to explore the potential-energy hypersurface of alkali counterions in the case $n=2$. We present tests of the results against available data and an evaluation of the convergence of the energy of the polymeric series towards a value of about $0.5 \mathrm{eV}$ per monomer.
\end{abstract}

Key words: Ionic Clusters; Molecular Vapours; Molten Salts.

\section{Introduction}

Liquid chloro- and bromo-aluminates, represented by the formula $(\mathrm{AX})_{1-x} \cdot\left(\mathrm{AlX}_{3}\right)_{x}$ where $\mathrm{X}=\mathrm{Cl}$ or $\mathrm{Br}$ and $A$ denotes an alkali or an organic cation, have been studied extensively for a number of years (for a recent review see [1]). Main attention has been given to the acidic range of composition $(0.5 \leq x \leq 1)$. Various evidence from several types of experiments and from molecular dynamics calculations shows that, starting from the mixture at $x=0.5$ as a liquid of tetrahedral $\left(\mathrm{AlX}_{4}\right)^{-}$anions and $\mathrm{A}^{+}$counterions, polymeric species of the type $\left(\mathrm{Al}_{n} \mathrm{X}_{3 n+1}\right)^{-}$with $n \geq 2$ are formed as the composition of the liquid mixture is varied towards pure $\mathrm{AlX}_{3}$. The pure compound forms a molecular liquid of $\mathrm{Al}_{2} \mathrm{X}_{6}$ dimers.

The available evidence has stimulated molecularorbital studies by $a b$ initio methods on the isolated $\left(\mathrm{Al}_{2} \mathrm{Cl}_{7}\right)^{-}$complex anion [2] as well as by semi-empirical methods on the $\left(\mathrm{Al}_{2} \mathrm{X}_{7}\right)^{-}$and $\left(\mathrm{Al}_{3} \mathrm{X}_{10}\right)^{-}$clusters [3-5]. It is known from these studies that the $\left(\mathrm{Al}_{2} \mathrm{X}_{7}\right)^{-}$cluster is formed by two tetrahedra sharing a halogen corner [2-4] and that for the $\left(\mathrm{Al}_{3} \mathrm{X}_{10}\right)^{-}$ species a chain-like structure of corner-sharing tetrahedra is more stable than a ring-like structure by 10
$-15 \mathrm{kcal} / \mathrm{mole}$ [3]. A preliminary ab initio study of the effect of an alkali counterion on the chlorine bridge in $\left(\mathrm{Al}_{2} \mathrm{Cl}_{7}\right)^{-}$has also been reported [3]. There remains an interest to study how a chain-like polymeric series of the $\left(\mathrm{Al}_{n} \mathrm{X}_{3 n+1}\right)^{-}$type converges structurally and energetically with increasing $n$ and to learn about the role of the chemical nature of the trivalent-metal ion, e.g. about the consequences of substituting the $\mathrm{Al}$ ions by $\mathrm{Ga}$ ions [6]. It also seems interesting to investigate the shape of the potential energy hypersurface for counterions around the anionic species.

In the present work we address the above questions by means of a microscopic ionic model. We start from an earlier study of the ionic interactions in $\mathrm{Al}_{2} \mathrm{Cl}_{6}$-based clusters [7] and extend it in Sect. 2 to determine models of the interionic forces for $\mathrm{Al}$ and $\mathrm{Ga}$ chlorides and bromides from properties of the $\mathrm{Ga}_{2} \mathrm{Cl}_{6}, \mathrm{Al}_{2} \mathrm{Br}_{6}$, and $\mathrm{Ga}_{2} \mathrm{Br}_{6}$ molecular dimers. These models are then used in Sect. 3 to evaluate the structure and the energetics of polymeric anions with $n \leq 4$ for the two trivalent-metal chlorides, and in Sect. 4 to investigate the local potential-energy minima for alkali counterions around the $\left(\mathrm{Al}_{2} \mathrm{X}_{7}\right)^{-}$and $\left(\mathrm{Ga}_{2} \mathrm{X}_{7}\right)^{-}$clusters. We conclude the paper in Sect. 5 with a brief summary and discussion of our results. 
Table 1. Interionic force parameters in $\mathrm{Al}$ and $\mathrm{Ga}$ chlorides and bromides (the subscrips $\mathrm{M}$ and $\mathrm{X}$ denote the trivalent-metal ion and the halogen ion; the values for $\mathrm{Al}_{2} \mathrm{Cl}_{6}$ are from [7]).

\begin{tabular}{|c|c|c|c|c|c|c|c|c|c|}
\hline & $z_{\mathrm{M}}$ & $z_{x}$ & $R_{\mathrm{M}}(\AA)$ & $\rho_{\mathrm{M}}(\AA)$ & $R_{\mathrm{X}}(\AA)$ & $\rho_{\mathrm{X}}(\AA)$ & $C_{X}\left(e^{5 / 2}\right)$ & $\alpha_{X}\left(\AA^{3}\right)$ & $\alpha_{\mathrm{S}}\left(\AA^{3} / \mathrm{e}\right)$ \\
\hline $\mathrm{Al}_{2} \mathrm{Cl}_{6}$ & 2.47 & $-0.82_{4}$ & 0.95 & 0.044 & 1.71 & 0.238 & 5.5 & 2.05 & 0.46 \\
\hline $\mathrm{Al}_{2} \mathrm{Br}_{6}$ & $2.42_{7}^{2}$ & $-0.80_{0}^{4}$ & 0.95 & 0.044 & 1.84 & 0.258 & 7.2 & 3.05 & 0.76 \\
\hline $\mathrm{Ga}_{2} \mathrm{Cl}_{6}$ & 2.36 & -0.78 & 0.97 & 0.045 & 1.71 & 0.238 & 5.5 & 2.05 & 0.46 \\
\hline $\mathrm{Ga}_{2} \mathrm{Br}_{6}$ & $2.36_{4}^{4}$ & $-0.78_{x}$ & 0.97 & 0.045 & 1.84 & 0.258 & 7.2 & 3.05 & 0.76 \\
\hline
\end{tabular}

\begin{tabular}{lllllllll}
\hline & & $M-X^{\mathrm{T}}$ & $\mathrm{M}-\mathrm{X}^{\mathrm{B}}$ & $\mathrm{M}-\mathrm{M}$ & $\mathrm{X}^{\mathrm{T}}-\mathrm{X}^{\mathrm{T}}$ & $\mathrm{X}^{\mathrm{B}}-\mathrm{X}^{\mathrm{B}}$ & $\angle \mathrm{X}^{\mathrm{T}}-\mathrm{M}-\mathrm{X}^{\mathrm{T}}$ & $\angle \mathrm{X}^{\mathrm{B}}-\mathrm{M}-\mathrm{X}^{\mathrm{B}}$ \\
\hline $\mathrm{Al}_{2} \mathrm{Cl}_{6}:$ & model & $\underline{2.065}$ & 2.28 & 3.20 & 3.59 & 3.23 & 121 & 90 \\
$\mathrm{Al}_{2} \mathrm{Br}_{6}:$ & model & $\underline{2.22}$ & 2.43 & $\underline{3.34}$ & 3.84 & 3.54 & 120 & 93 \\
& ED & 2.22 & 2.41 & 3.34 & 3.90 & 3.48 & 122.8 & 92.3 \\
& $\mathrm{QC}$ & 2.25 & 2.46 & 3.43 & 3.91 & 3.52 & 120.8 & 91.4 \\
$\mathrm{Ga}_{2} \mathrm{Cl}_{6}:$ & model & 2.13 & 2.34 & 3.32 & 3.70 & 3.29 & 121 & 90 \\
$\mathrm{Ga}_{2} \mathrm{Br}_{6}:$ & model & 2.27 & 2.48 & $\underline{3.43}$ & 3.93 & 3.59 & 120 & 93 \\
& ED & 2.25 & 2.45 & 3.43 & 4.04 & 3.49 & 128.1 & 91.1 \\
& $\mathrm{QC}$ & 2.29 & 2.50 & 3.52 & 4.00 & 3.56 & 122.1 & 90.7 \\
\hline
\end{tabular}

Table 2. Equilibrium structure of $\mathrm{Al}_{2} \mathrm{Cl}_{6}$, $\mathrm{Al}_{2} \mathrm{Br}_{6}, \mathrm{Ga}_{2} \mathrm{Cl}_{6}$ and $\mathrm{Ga}_{2} \mathrm{Br}_{6}$ (bond lengths in $\AA$ and bond angles in degrees; the values for $\mathrm{Al}_{2} \mathrm{Cl}_{6}$ are from [7]).

\section{Interionic Force Model}

In an earlier study of $\mathrm{Al}_{2} \mathrm{Cl}_{6}$ and related aluminium chloride clusters including $\left(\mathrm{Al}_{2} \mathrm{Cl}_{7}\right)^{-}$[7] two of us constructed an expression for the potential energy $U\left(\left\{\boldsymbol{r}_{i j}\right\},\left\{\boldsymbol{p}_{i}\right\}\right)$ of an ionic cluster as a function of the interionic bond vectors $\boldsymbol{r}_{i j}$ and of the electric dipole moments $\boldsymbol{p}_{i}$. This involved an extension of the shell model (also known as the deformation dipole model) for the lattice dynamics of ionic and semiconducting crystals [8]. A basic quantal justification for this approach to molecular structure has been given for alkali halides by means of exchange perturbation theory $[9,10]$. For the detailed expressions entering $U\left(\left\{\boldsymbol{r}_{i j}\right\},\left\{\boldsymbol{p}_{i}\right\}\right)$, which are also used in the present study, we refer to the earlier work [7].

In the determination of the model parameters for $\mathrm{Al}_{2} \mathrm{Br}_{6}$ we closely follow the procedure already developed in [7] for the $\mathrm{Al}_{2} \mathrm{Cl}_{6}$ dimer. We start from an earlier study of the $\left(\mathrm{AlBr}_{4}\right)^{-}$cluster [11] and refine it with special attention to the modelling of the bridge formed by two bromines in the dimer. This is done by introducing an effective valence $z_{\mathrm{Br}}$ for the bromine and polarizabilities $\alpha_{\mathrm{Br}}$ and $\alpha_{\mathrm{s}}$, which describe dipole induction by the electric field on the halogen and its saturation by short-range overlap distortions of its electron shells. We determine these quantities for $\mathrm{Al}_{2} \mathrm{Br}_{6}$ from the measured value of its topmost stretching-mode frequency $\left(\nu_{3}=500 \mathrm{~cm}^{-1}\right.$ [12] $)$ and from the $\mathrm{Al}-\mathrm{Al}$ bond length $(3.34 \AA)$ and the Al-terminal bromine bond length $(2.22 \AA)$ as measured in an electron diffraction experiment [13]. The other model parameters for the bromine ion (the van der Waals coefficient $C_{\mathrm{Br}}$, the ionic radius $R_{\mathrm{Br}}$, and the stiffness parameter $\rho_{\mathrm{Br}}$ describing the contribution of the bromines in the Busing form [14] of the Al-Br overlap repulsions) are taken from [11], while the ionic radius $R_{\mathrm{Al}}$ and the stiffness parameter $\rho_{\mathrm{Al}}$ for the $\mathrm{Al}$ ion are taken from [7]. Overall charge neutrality determines $z_{\mathrm{Al}}=-3 z_{\mathrm{Br}}$.

The extension of these model parameters to the $\mathrm{Ga}$ dimers is immediate. We use as input data for $\mathrm{Ga}_{2} \mathrm{Br}_{6}$ the measured $\mathrm{Ga}-\mathrm{Ga}$ bond length ( $3.43 \AA$ ) from electron diffraction experiments [13] and the measured value of the breathing mode of the molecular dimer in the pure molecular liquid $\left(\nu_{\mathrm{b}}=290 \mathrm{~cm}^{-1}\right.$ [15]) to determine the effective valence and the ionic radius of $\mathrm{Ga}$, on the assumption that the other model parameters can be transferred from the $\mathrm{Al}_{2} \mathrm{Br}_{6}$ dimer. For $\mathrm{Ga}_{2} \mathrm{Cl}_{6}$, on the other hand, transfer of all model parameters from $\mathrm{Ga}_{2} \mathrm{Br}_{6}$ and from $\mathrm{Al}_{2} \mathrm{Cl}_{6}$ yields immediate agreement with the rather scanty experimental evidence on the Raman frequencies of the dimer in the liquid as measured by Boghosian et al. [16]. In particular, we calculate a frequency of $411 \mathrm{~cm}^{-1}$ for the breathing mode against a measured value of $410 \mathrm{~cm}^{-1}[16]$.

Table 1 shows the sets of model parameters that we have used in the calculations reported in the sequel for the $\mathrm{Al}$ and $\mathrm{Ga}$ halide polymers. It is evident that all these materials are reasonably close to the ideal ionic model, as can be judged from the values of the effective valences. The deviations from ideal ionicity are slightly larger for bromides and for Ga compounds. 
Table 3. Frequencies of vibrational modes for $\mathrm{Al}_{2} \mathrm{Br}_{6}$ and $\mathrm{Ga}_{2} \mathrm{Br}_{6}$ (in $\mathrm{cm}^{-1}$; values in curly brackets are estimated).

\begin{tabular}{lcccc}
\hline & \multicolumn{2}{c}{$-\mathrm{Al}_{2} \mathrm{Br}_{6}-$} & \multicolumn{2}{c}{$-\mathrm{Ga}_{2} \mathrm{Br}_{6}-$} \\
& model & Expt, gas [12] & model & Expt, liquid [15] \\
\hline $\mathrm{B}_{1 \mathrm{u}}$ & 10 & $\{8\}$ & 9 & - \\
$\mathrm{A}_{\mathrm{u}}$ & 34 & $\{30\}$ & 31 & - \\
$\mathrm{A}_{\mathrm{g}}$ & 59 & 59 & 55 & 62 \\
$\mathrm{~B}_{3 \mathrm{~g}}$ & 59 & $\{67\}$ & 56 & - \\
$\mathrm{B}_{2 \mathrm{~g}}$ & 75 & 76 & 63 & 69 \\
$\mathrm{~B}_{2 \mathrm{u}}$ & 80 & 90 & 71 & - \\
$\mathrm{B}_{3 \mathrm{u}}$ & 86 & $\{110\}$ & 76 & - \\
$\mathrm{B}_{1 \mathrm{u}}$ & 104 & 112 & 84 & 84 \\
$\mathrm{~B}_{1 \mathrm{~g}}$ & 110 & 114 & 93 & - \\
$\mathrm{A}_{\mathrm{g}}$ & 159 & 139 & 132 & 118 \\
$\mathrm{~B}_{3 \mathrm{u}}$ & 170 & 199 & 133 & - \\
$\mathrm{B}_{1 \mathrm{~g}}$ & 199 & 203 & 175 & - \\
$\mathrm{A}_{\mathrm{g}}$ & 217 & $\{250\}$ & 202 & 201 \\
$\mathrm{~B}_{2 \mathrm{u}}$ & 355 & 346 & 239 & - \\
$\mathrm{B}_{3 \mathrm{u}}$ & 366 & 376 & 269 & - \\
$\mathrm{A}_{\mathrm{g}}$ & 419 & 409 & $\underline{290}$ & 290 \\
$\mathrm{~B}_{2 \mathrm{~g}}$ & 492 & 489 & 333 & 341 \\
$\mathrm{~B}_{1 \mathrm{u}}$ & 500 & 500 & 334 & - \\
\hline
\end{tabular}

Table 2 completes the comparison of our results for the equilibrium structure of the molecular dimers with measured values from electron diffraction (ED, from [13]) and with the results of quantum chemical calculations (QC, from [15]). The symbols $\mathrm{X}^{\mathrm{T}}$ and $\mathrm{X}^{\mathrm{B}}$ denote a terminal and a bonding halogen, respectively. Values fitted to experiment are underlined.

Table 3 compares our results for the vibrational frequencies of $\mathrm{Al}_{2} \mathrm{Br}_{6}$ and $\mathrm{Ga}_{2} \mathrm{Br}_{6}$ with experimental data on gaseous $\mathrm{Al}_{2} \mathrm{Br}_{6}[12]$ and on the $\mathrm{GaBr}_{3}$ molecular liquid [15], respectively. The agreement between calculated and measured spectra in Table 3 can be considered as very reasonable.

\section{Equilibrium Structures and Energetics of the Polymeric Series}

As already discussed in earlier work (see e.g. [7]), the potential energy landscape for the $\left(\mathrm{Al}_{2} \mathrm{Cl}_{7}\right)^{-}$anion is very complex. Four structures formed from cornersharing tetrahedra are almost degenerate in energy and differ only for internal rotations giving different relative orientations to the two terminal $\mathrm{AlCl}_{3}$ groups. However, of these the only mechanically stable structure at zero temperature is the $\mathrm{C}_{2}$ one, which is obtained from a $\mathrm{C}_{2 \mathrm{v}}$ structure having an eclipsed arrangement of the terminal groups through opposite rotations of these groups by $30^{\circ}$ around the $\mathrm{Al}-\mathrm{Cl}^{\mathrm{B}}$ bond. The other structures have at least one imaginary
Table 4. Calculated equilibrium structure of the $\left(\mathrm{Al}_{2} \mathrm{Cl}_{7}\right)^{-}$, $\left(\mathrm{Al}_{2} \mathrm{Br}_{7}\right)^{-},\left(\mathrm{Ga}_{2} \mathrm{Cl}_{7}\right)^{-}$and $\left(\mathrm{Ga}_{2} \mathrm{Br}_{7}\right)^{-}$anions in the $\mathrm{C}_{2}$ configuration (the ranges of values shown for bond lengths and bond angles span those appropriate to inequivalent terminal halogens; the values for $\left(\mathrm{Al}_{2} \mathrm{Cl}_{7}\right)^{-}$are from [7]. Bond lengths in $\AA$ and bond angles in degrees).

\begin{tabular}{lcrrc}
\hline & $\mathrm{M}-\mathrm{X}^{\mathrm{T}}$ & $\mathrm{M}-\mathrm{X}^{\mathrm{B}}$ & $\angle \mathrm{X}^{\mathrm{T}}-\mathrm{M}-\mathrm{X}^{\mathrm{T}}$ & $\angle \mathrm{X}^{\mathrm{B}}-\mathrm{M}-\mathrm{X}^{\mathrm{B}}$ \\
\hline$\left(\mathrm{Al}_{2} \mathrm{Cl}_{7}\right)^{-}$ & $2.10-2.12$ & 2.35 & $100-108$ & 111 \\
$\left(\mathrm{Al}_{2} \mathrm{Br}_{7}\right)^{-}$ & $2.25-2.28$ & 2.52 & $99-110$ & 108 \\
$\left(\mathrm{Ga}_{2} \mathrm{Cl}_{7}\right)^{-}$ & $2.16-2.18$ & 2.40 & $100-107$ & 111 \\
$\left(\mathrm{Ga}_{2} \mathrm{Br}_{7}\right)^{-}$ & $2.30-2.33$ & 2.56 & $99-109$ & 108 \\
\hline
\end{tabular}

mode frequency and therefore correspond to a multiplicity of saddle points separating several equivalent true minima. We may expect that at finite temperature the molecular ion will be executing rapid fluctuations between its various structures.

We have found that these structural properties hold for this anion in all other trihalides of present interest. Table 4 reports some of our results for equilibrium bond lengths and bond angles.

The same flexibility under rotations around the Al$\mathrm{Cl}^{\mathrm{B}}$ bonds in chain-like structures is displayed by the $\left(\mathrm{Al}_{3} \mathrm{Cl}_{10}\right)^{-}$and $\left(\mathrm{Ga}_{3} \mathrm{Cl}_{10}\right)^{-}$trimeric anions. We find four structures for these anions, which are reported in Figure 1. All these chain-like structures are mechanically stable and differ very little in binding energy, at the level of hundredths of an $\mathrm{eV}$. Again, rapid fluctuations in the hot melt are indicated.

The two structures of deepest energy are shown in Figs. 1.1 and 1.2. The trimer in Fig. 1.2 has a "stretched" configuration corresponding to the metal ions and bonding chlorines lying all in the same plane, while the structure in Fig. 1.1, which actually has a slightly deeper energy, is obtained from it by rotations of the terminal groups out of the plane. Relative to the values reported for the dimeric anions in Table 4 , the bond lengths in these two structures of the trimeric anions are somewhat contracted in the central ionic group and somewhat expanded or (for the terminal chlorines) essentially unchanged in the external groups.

Figure 1.3 shows a "winged" structure for the trimeric anions, in which the bonds of the terminal metal ions to the bonding chlorines are twisted out of the plane. Finally, Fig. 1.4 shows a "cart" structure, in which the planar skeleton of the molecule is preserved but the central and terminal chlorines go into a staggered configuration. The "stretched", "winged", and "cart" structures for $\left(\mathrm{Al}_{3} \mathrm{Cl}_{10}\right)^{-}$have previously 
1.1

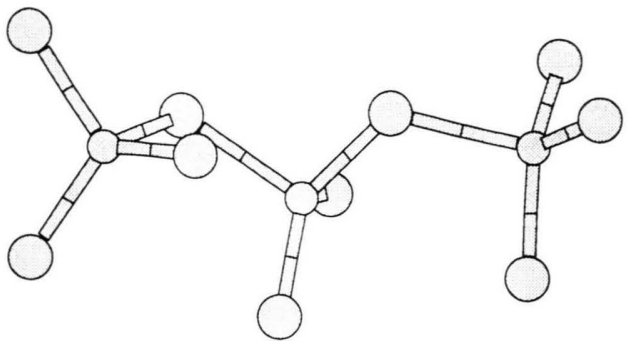

1.2

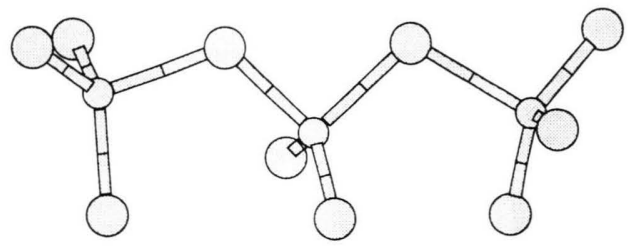

1.3

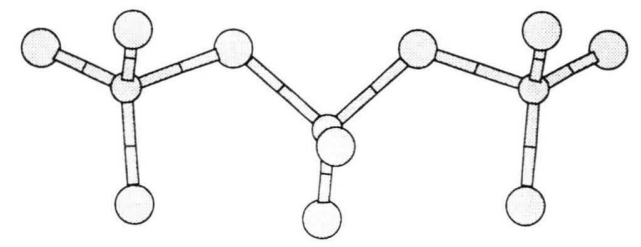

1.4

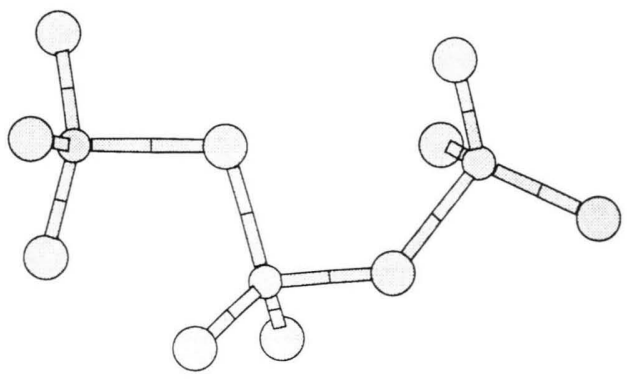

Fig. 1. Ball-and-stick models of four stable structures of the $\left(\mathrm{M}_{3} \mathrm{Cl}_{10}\right)^{-}$anion for $\mathrm{M}=\mathrm{Al}$ or $\mathrm{Ga}$ (see the discussion given in the text).

been reported from semi-empirical molecular orbital calculations by Dymek et al. [5].

Figure 2 shows a "stretched" chain-like configuration that we have found for the $\left(\mathrm{Al}_{4} \mathrm{Cl}_{13}\right)^{-}$and $\left(\mathrm{Ga}_{4} \mathrm{Cl}_{13}\right)^{-}$anion. All metal ions and bonding chlorines forming the backbone of the tetramer lie in a single plane. The bond lengths to the central bonding chlorine are $2.34 \AA$ in $\left(\mathrm{Al}_{4} \mathrm{Cl}_{13}\right)^{-}$and $2.40 \AA$ in $\left(\mathrm{Ga}_{4} \mathrm{Cl}_{13}\right)^{-}$, i. e. practically the same as those reported in Table 4 for $\left(\mathrm{Al}_{2} \mathrm{Cl}_{7}\right)^{-}$and $\left(\mathrm{Ga}_{2} \mathrm{Cl}_{7}\right)^{-}$. For the other
Table 5. Incremental binding energy $\Delta E^{(n)}$ of the $\left(\mathrm{Al}_{n} \mathrm{Cl}_{3 n+1}\right)^{-}$and $\left(\mathrm{Ga}_{n} \mathrm{Cl}_{3 n+1}\right)^{-}$series as a function of $n$ (in $\mathrm{eV}$ ).

\begin{tabular}{lcccc}
\hline & $n=1$ & $n=2$ & $n=3$ & $n=4$ \\
\hline$\left(\mathrm{Al}_{n} \mathrm{Cl}_{3 n+1}\right)^{-}$ & 2.29 & 0.76 & 0.61 & 0.49 \\
$\left(\mathrm{Ga}_{n} \mathrm{Cl}_{3 n+1}\right)^{-}$ & 2.18 & 0.78 & 0.61 & 0.53 \\
\hline
\end{tabular}

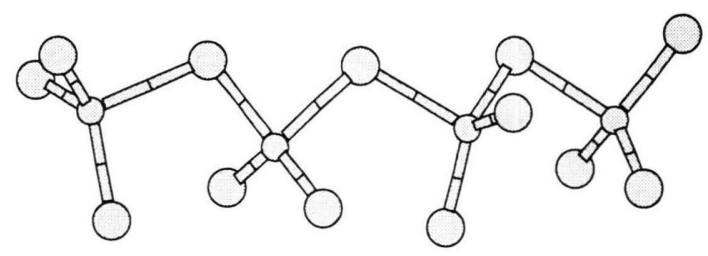

Fig. 2. A ball-and-stick model of the "stretched" structure of the $\left(\mathrm{M}_{4} \mathrm{Cl}_{13}\right)^{-}$anion for $\mathrm{M}=\mathrm{Al}$ or $\mathrm{Ga}$.

bond lengths similar comments apply as those given above for $\left(\mathrm{Al}_{3} \mathrm{Cl}_{10}\right)^{-}$and $\left(\mathrm{Ga}_{3} \mathrm{Cl}_{10}\right)^{-}$.

We conclude this section by reporting in Table 5 the increments $\Delta E^{(n)}$ in binding energy of the $\left(\mathrm{Al}_{n} \mathrm{Cl}_{3 n+1}\right)^{-}$and $\left(\mathrm{Ga}_{n} \mathrm{Cl}_{3 n+1}\right)^{-}$poly-anions on increasing $n$ by unity in the range $1 \leq n \leq 4$. We have defined $\Delta E^{(n)} \equiv E_{\mathrm{b}}^{(n)}-E_{\mathrm{b}}^{(n-1)}-E_{\mathrm{b}}\left(\mathrm{MCl}_{3}\right)$, with $E_{\mathrm{b}}^{(n)}$ the binding energy of the $n$-th member of the polymeric series and $E_{\mathrm{b}}\left(\mathrm{MCl}_{3}\right)$ the binding energy of $\mathrm{MCl}_{3}$. It is evident that the increase in binding energy of the two polymeric series on addition of an $\mathrm{AlCl}_{3}$ or $\mathrm{GaCl}_{3}$ group is converging quite rapidly to a constant amount of about $0.5 \mathrm{eV}$.

\section{Energy Minima for Alkali Counterions}

We report in this section our results on the potential energy minima of alkali counterions near dimeric anions, with main attention to the cases $\mathrm{A}=\mathrm{Li}, \mathrm{Na}$ or $\mathrm{K}$ around an $\left(\mathrm{Al}_{2} \mathrm{Cl}_{7}\right)^{-}$or an $\left(\mathrm{Al}_{2} \mathrm{Br}_{7}\right)^{-}$anion. Similar results have been obtained for a $\mathrm{Na}$ counterion near $\left(\mathrm{Ga}_{2} \mathrm{Cl}_{7}\right)^{-}$or $\left(\mathrm{Ga}_{2} \mathrm{Br}_{7}\right)^{-}$. The model parameters describing the overlap repulsion and the polarizability of alkali cations are as in earlier work on fluorides [17].

We find no qualitative dependence on the halogen, but a somewhat different structural behaviour for $\mathrm{Li}$ as opposed to $\mathrm{Na}$ and $\mathrm{K}$. Figure 3 shows the deepestenergy configuration for $\mathrm{Na}$ or $\mathrm{K}$ around an $\left(\mathrm{Al}_{2} \mathrm{X}_{7}\right)^{-}$ anion. The alkali cation is coordinated by four of the terminal halogens, the bond length being $3.60 \AA$ in the case of $\mathrm{KAl}_{2} \mathrm{Cl}_{7}$. The corresponding $\mathrm{K}-\mathrm{Cl}^{\mathrm{B}}$ distance is $4.99 \AA$ and the $\mathrm{Al}-\mathrm{Cl}^{\mathrm{B}}$ - $\mathrm{Al}$ bond angle is $115^{\circ}$. In semiempirical molecular orbital calculations on $\mathrm{AAl}_{2} \mathrm{Cl}_{7}$ 


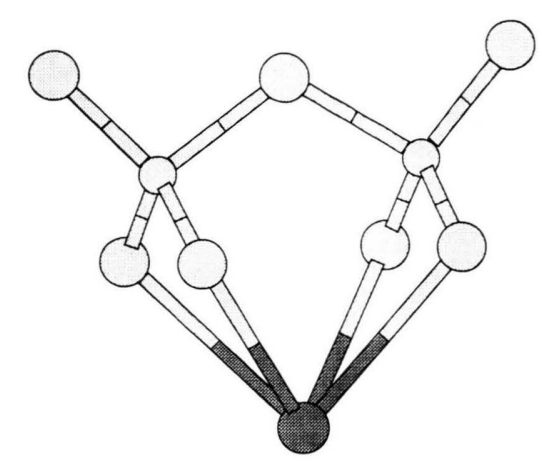

Fig. 3. A ball-and-stick model of the deepest-energy structure of the $\mathrm{KAl}_{2} \mathrm{X}_{7}$ cluster for $\mathrm{X}=\mathrm{Cl}$ or $\mathrm{Br}$. The $\mathrm{K}$ ion is shown as a dark sphere.

Blander et al. [3] reported a significant decrease of this bond angle on the approach of an alkali counterion, to a value of about $100^{\circ}$ for $\mathrm{K}$ at a $\mathrm{K}-\mathrm{Cl}^{\mathrm{B}}$ distance of $5 \AA$. There is, therefore, disagreement in detail between our model and their results. However, from an X-ray diffraction experiment on $\mathrm{KAl}_{2} \mathrm{Br}_{7}$ crystals Rytter et al. [18] reported an $\mathrm{Al}-\mathrm{Br}^{\mathrm{B}}$ - $\mathrm{Al}$ bond angle of $109.3^{\circ}$ and $\mathrm{K}-\mathrm{Br}$ bond lengths in the range from 3.3 to $4.0 \AA$. Our corresponding results for the isolated $\mathrm{KAl}_{2} \mathrm{Br}_{7}$ cluster are $112.6^{\circ}$ and $3.74 \AA$.

Still considering the case of $\mathrm{AAl}_{2} \mathrm{X}_{7}$ with $\mathrm{A}=\mathrm{Na}$ or $\mathrm{K}$, we find two further distinct energy minima for the alkali counterion at a slightly higher energy than for the minimum shown in Figure 3. These minima correspond to (i) bonding of the counterion to the three terminal halogens in one of the $\mathrm{AlX}_{3}$ groups, and (ii) bonding on top of the halogen bridge to the bridging halogen and to three further terminal halogens. It is evident from our calculations, therefore, that within our model the counterions are essentially free to move around the isolated poly-anion. This is consistent with essentially free migration of counterions in liquid mixtures.

[1] Z. Akdeniz, D. L. Price, M.-L. Saboungi, and M. P. Tosi, Plasmas and Ions 1, 3 (1998).

[2] L. A. Curtiss, Proc. Joint Int. Symp. Molten Salts, ed. G. Mamantov; The Electrochemical Society, Pennington 1987 , p. 185.

[3] M. Blander, E. Bierwagen, K. G. Calkins, L. A. Curtiss, D. L. Price, and M.-L. Saboungi, J. Chem. Phys. 97, 2733 (1992).

[4] L. P. Davis, C. J. Dymek, J. J. P. Stewart, H. P. Clark, and W. J. Lauderdale, J. Amer. Chem. Soc. 1985, 5041.
As already noted, some details of the potential energy hypersurface for a $\mathrm{Li}$ counterion are somewhat different from the situation pertaining to $\mathrm{Na}$ and $\mathrm{K}$. The smaller ionic size of $\mathrm{Li}$ tends to favour threefold over fourfold coordination to the halogens, and in particular we find that the deeper energy minimum corresponds to binding to only three of the four bonding halogens shown in Figure 3. Again, free migration of the Li counterions is indicated.

\section{Concluding Remarks}

We have in this work determined a microscopic model of ionic interactions in aluminium and gallium trihalides and applied it to study the polymeric anion series which are formed in liquid $\mathrm{Al}$-alkali and $\mathrm{Ga}$ alkali halide mixtures. We have especially focused on the multiplicity of structures which are allowed for these chain-like anions by the considerable freedom of rotation of molecular groups around internal bonds and on the convergence of the value of the binding energy per monomer with increasing chain length. We have also examined the main features of the potential energy landscape for alkali counterions around dimeric anions.

The reasonable description afforded by our model for these complex ionic clusters suggests that it should find useful applications in further studies of these materials in the liquid state.

\section{Acknowledgements}

Three of us (Z.A., M.Ç., and Z.Ç.) acknowledge support received from the Turkish Scientific and Technological Research Council (Tubitak). Z. A. also acknowledges support from the Research Fund of the University of Istanbul under Project Number Ö-681/121099 and wishes to thank the Scuola Normale Superiore di Pisa for their hospitality during the final stages of this work.

[5] C. J. Dymek, J. S. Wilkes, M.-A. Einarsrud, and H. A. Øye, Polyhedron 7, 1139 (1988).

[6] K. R. Seddon, Proc. Int. George Papatheodorou Symp., ed. S.Boghosian et al.; ICE/HT, Patras 1999, p. 131.

[7] Z. Akdeniz and M. P. Tosi, Z. Naturforsch. 54a, 180 (1999).

[8] See e. g. R. A. Cochran, Crit. Rev. Solid State Sci. 2, 1 (1971); J. R. Hardy and A. M. Karo, The Lattice Dynamics and Statics of Alkali Halide Crystals; Plenum Press, New York 1979. 
[9] M. P. Tosi and M. Doyama, Phys. Rev. 160, 716 (1967).

[10] P. Brumer and M. Karplus, J. Chem. Phys. 58, 3903 (1973).

[11] Wang Li and M. P. Tosi, Nuovo Cim. D 10, 1497 (1988).

[12] M. W. Chase, C. A. Davies, J. R. Downey, D. J. Frurip, R. A. McDonald, and A. N. Syverud, J. Phys. Chem. Ref. Data 14, Suppl. No. 1 (1985).

[13] Q. Shen, Diss. Abstr. (Int.) B 34, 3735 (1974).
[14] W. R. Busing, Trans. Amer. Crystallogr. Assoc. 6, 57 (1970).

[15] A. D. Alvarenga, M.-L. Saboungi, L. A. Curtiss, M. Grimsditch, and L. E. McNeil, Molec. Phys. 81, 409 (1994).

[16] S. Boghosian, D. A. Karydis, and G. A. Voyiatzis, Polyhedron 12, 771 (1993).

[17] Z. Akdeniz, Z. Çiçek, A. Karaman, G. Pastore, and M. P. Tosi, Z. Naturforsch. 54a, 575 (1999).

[18] E. Rytter, B. E. D. Rytter, H. A. Øye, and J. KroghMoe, Acta Cryst. B29, 1541 (1973). 